\title{
New Antidiabetic and Free-Radical Scavenging Potential of Strictosamide in Sarcocephalus pobeguinii Ground Bark Extract via Effect-Directed Analysis
}

\author{
Imanuel Yüce, ${ }^{*} \dagger$ Huguette Agnaniet, ${ }^{*},+$ and Gertrud E. Morlock* $* \dagger$ \\ ${ }^{\dagger}$ Institute of Nutritional Science and Interdisciplinary Research Center (IFZ), Justus Liebig University Giessen, Heinrich-Buff-Ring \\ 26-32, 35392 Giessen, Germany \\ ${ }^{\ddagger}$ Laboratory of Natural Substances and Organometallic Synthesis, University of Sciences and Techniques of Masuku, Faculty of \\ Sciences BP. 943, Franceville, Gabon
}

Supporting Information

\begin{abstract}
The active principle of most traditional medicines is not known, as for Sarcocephalus pobeguinii Hua ex Pellegr. bark extract. It is used as an antidiabetic drug in Gabonese folk medicine. Diabetes mellitus is increasing globally, and products from natural sources are gaining interest as a remedy. As the active antidiabetic compounds have not been characterized so far, a mobile phase for highperformance thin-layer chromatography (HPTLC) was newly developed to target single active compounds in the unpolar ground bark extract of $S$. pobeguinii by effect-directed analysis (EDA). One natural compound zone showed multipotent activities by effect-directed detection, that is, antidiabetic, cholinesterase inhibiting, and antioxidative activities. Its
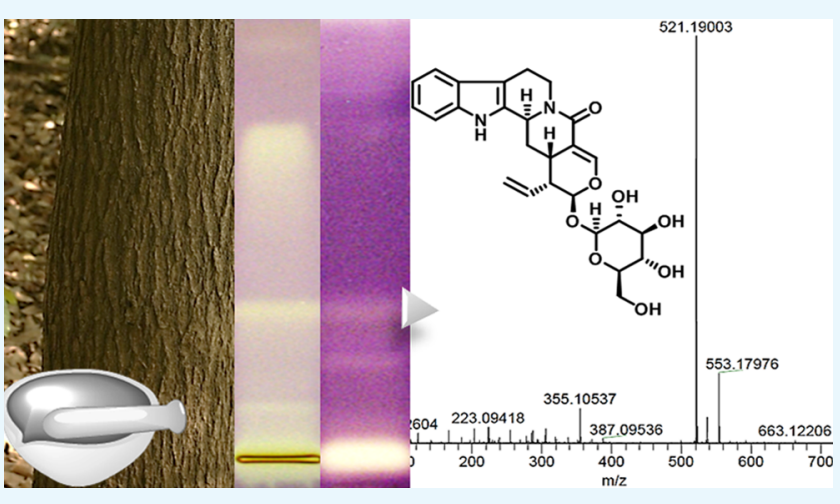
characterization was performed via online elution of the active substance zone from the HPTLC layer into the high-resolution mass spectrometry (HRMS) system. Important parts of the structure were assigned by MS/MS experiments and led to the preliminary assignment of strictosamide, an indole alkaloid. The saccharide moiety of the active molecule was characterized with a selective derivatization reagent (diphenylamine aniline phosphoric acid reagent). Strictosamide was already reported as a constituent of the extract, and its cholinesterase inhibiting property was confirmed. However, it was newly found to be active as a free-radical scavenger and $\alpha$-glucosidase inhibitor, which might partially explain the successful use as antidiabetic and antioxidative folk medicine. The fast bioprofiling by HPTLC-UV/ vis/FLD-EDA-HRMS was proven to be suited as an analytical tool for the discovery of multipotent active compounds.
\end{abstract}

\section{INTRODUCTION}

In the past, African plants showed a few times to be potent for the fight against a variety of diseases. ${ }^{1}$ Among Gabonese medicinal plants, Sarcocephalus pobeguinii Hua ex Pellegr. syn. Nauclea pobeguinii was investigated, as it was used in folk medicine against different diseases, ${ }^{2-4}$ for example, diabetes mellitus, ${ }^{4,5}$ hypertension, ${ }^{4}$ and urogenital infections. ${ }^{6} \mathrm{~S}$. pobeguinii is a tree with a size of $6-30 \mathrm{~m}$. Its bark is white to gray, brown, and the fruits are eatable. ${ }^{7}$ In folk medicine, the leaves and bark of $S$. pobeguinii were utilized to produce drugs. ${ }^{4,8}$

This plant belongs to the Rubiaceae family, known for containing iridoids, anthraquinones, triterpenes, indole alkaloids, and further alkaloids as compound classes. ${ }^{9}$ Aqueous or ethanolic extracts of $S$. pobeguinii bark were tested in vivo and in vitro for their antimalarial, ${ }^{10,11}$ antioxidative, ${ }^{4,12}$ and antidiabetic activities ( $\alpha$-glucosidase). ${ }^{4,13}$ Their chromatographic investigation with high-performance liquid chromatography-solid-phase extraction-nuclear magnetic resonance spec- troscopy (HPLC-SPE-NMR) and ultraperformance liquid chromatography-mass spectrometry revealed indole alkaloid contents. $^{14}$ One main compound (5.6\%) was strictosamide. ${ }^{15}$ Strictosamide was screened for antiplasmodial, cytotoxic, ${ }^{10}$ antiviral, antiproliferative, ${ }^{16}$ anticarcinogenic (drug-resistant cancer cells), ${ }^{17}$ acetyl-/butyrylcholinesterase (AChE, BChE) inhibiting, ${ }^{18}$ and anti-inflammatory activities. ${ }^{19}$ In order to understand active principles in folk medicines or find further natural medicines, it is important to select a chromatographic method capable for powerful effect-directed screening and for combination with structure elucidation techniques, for example, NMR, infrared spectroscopy, and high-resolution MS (HRMS). Among present strategies for the combination of column or planar chromatography with effect-directed analysis (EDA), high-performance thin-layer chromatography

Received: September 20, 2018

Accepted: January 11, 2019

Published: March 8, 2019 
(HPTLC) was considered to be most straightforward, efficient, versatile, and flexible for detection of single bioactive molecules in complex plant extracts. ${ }^{20-25}$ The visual interpretation of the obtained data as an image enabled a fast comparative bioprofiling. Especially, the robustness of the separation for crude extracts, the parallel separation, and capability for multidetection, including effect-directed detections with chemical, biochemical, or biological assays, are crucial assets, if compared to HPLC or gas chromatography methods.

In this study, crucial assets of HPTLC-EDA were exploited to rapidly discover multipotent active compounds in the unpolar extract of $S$. pobeguinii ground bark. Their structure was characterized via a selective derivatization on the HPTLC layer, HRMS, and $\mathrm{MS}^{2}$ experiments of online eluted zones as well as comparison with literature. The potential of a fast and streamlined top-down analysis, that is, from the effect to the responsible compound, is demonstrated.

\section{RESULTS AND DISCUSSION}

Development of the Solvent System. Nine different MPs on HPTLC plates silica gel 60 were investigated for analysis of the unpolar compounds in the S. pobeguinii ground bark extract (Table 1 , selected based on experience). The MPs

Table 1. Investigated MPs 1-9 for Separation of the Unpolar Compounds in the S. pobeguinii Ground Bark Extract

\begin{tabular}{cll} 
MP & \multicolumn{1}{c}{ solvent system } & \multicolumn{1}{c}{ volume ratio } \\
\hline 1 & chloroform-methanol-water $^{a}$ & $35-15-2$ \\
2 & toluene-ethanol-water-acetic acid & $35-20-2-1$ \\
3 & toluene-ethanol-water & $35-20-2$ \\
4 & toluene- $n$-butanol-water & $35-15-2$ \\
5 & $i$-propyl acetate- $n$-butanol-water & $35-25-2$ \\
6 & $n$-butanol-water-acetic acid & $7-2-2$ \\
7 & ethyl acetate-ethyl methyl ketone-water-formic & $5-3-1-1$ \\
& acid & \\
8 & toluene- $i$-propanol-water-ammonia $25 \%$ & $13-10-0.3-0.3$ \\
9 & toluene- $n$-butanol-water & $30-20-2$
\end{tabular}

${ }^{a}$ Solvent system performed according to the literature. ${ }^{4}$

1,6 , and 7 were suited for investigation of the polar extract part, as illustrated in the respective chromatograms (Figure 1). Middle polar compounds were separated with MPs 2, 3, 5, and 8. However, the most promising solvent for discrimination of the matrix was MP4, that is, toluene- $n$-butanol-water 35:15:2 $(\mathrm{v} / \mathrm{v} / \mathrm{v})$. The elution strength of MP4 was slightly increased to

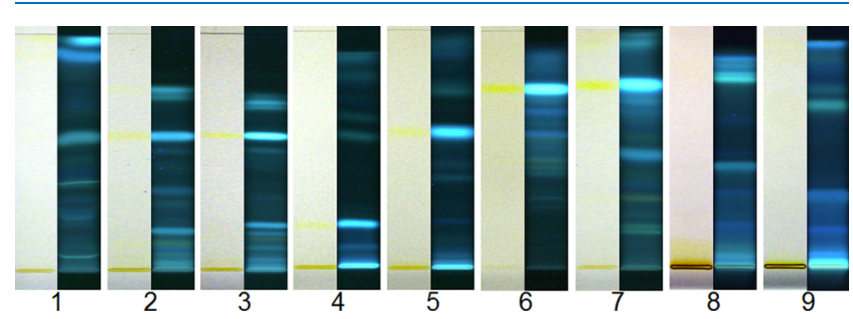

Figure 1. HPTLC-vis/FLD chromatograms of $S$. pobeguinii ground bark extract obtained by different mobile phase systems on HPTLC plate silica gel 60 (Table 1); $20 \mu \mathrm{g} /$ band for MPs $1-3,10 \mu \mathrm{g} / \mathrm{band}$ for MPs 4-7, and $60 \mu \mathrm{g} / \mathrm{band}$ for MPs 8 and 9 (both latter ones were used for EDA). toluene-n-butanol-water 30:20:2 (v/v/v) to separate more selectively the unpolar part of the extract and let remain the polar matrix at the start zone, as evident in the resulting chromatograms of MP 9. It is important to minimize co-eluting compounds in HPTLC, which increases the evidence of the results obtained by EDA or MS. Hence, in this study, the unpolar extract was investigated to obtain a suited separation of unpolar compounds. However, in future, the more polar components need to be investigated, too, as activities were also observed for the start zone (Figure 2).

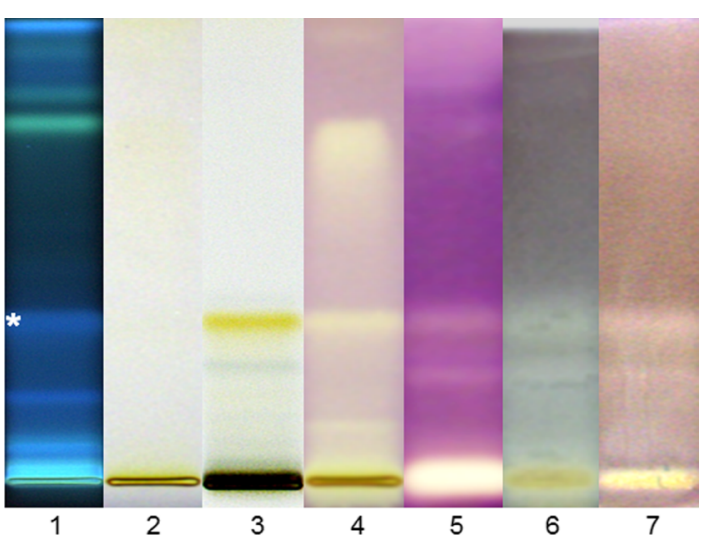

Figure 2. HPTLC images of S. pobeguinii ground bark extract (100 $\mu \mathrm{g} /$ band) separated on HPTLC plates silica gel 60 with MP 9 after detection at UV $366 \mathrm{~nm}$ (1), white light illumination (2), the latter after derivatization with diphenylamine aniline phosphoric acid reagent (3) and effect-directed detection with $\mathrm{DPPH}^{\bullet}$ (4), $\alpha$ glucosidase (5), AChE (6), and BChE assays (7).

Multi- and Effect-Directed Detection. The $S$. pobeguinii extract $(100 \mu \mathrm{g} / 8 \mathrm{~mm}$ band) was applied six times on the HPTLC plate with a track distance of $\geq 30 \mathrm{~mm}$ and separated with MP 9. For multidetection, the plate was cut in between the tracks (smartCut Plate Cutter, CAMAG) and the six plate pieces were subjected to seven different detection modes. The resulting fingerprints of the unpolar $S$. pobeguinii extract part were different, but the zone at $h R_{\mathrm{F}} 31$ was prominently detected in all of them (Figure 2). It was natively fluorescent at UV $366 \mathrm{~nm}$ (1) and not visible at white light illumination (2). Via derivatization with the diphenylamine aniline phosphoric acid reagent (3), the zone at $h R_{\mathrm{F}} 31$ turned into a strong yellow color, indicating a saccharide moiety, which was assumed to be a glycoside at the given unpolar separation. Below, another glycoside zone (less intense and blue) was evident in the unpolar S. pobeguinii extract part.

After effect-directed detection by the 2,2-diphenyl-1picrylhydrazyl $\left(\mathrm{DPPH}^{\bullet}\right)$ assay (4), three bands were evident in the unpolar $S$. pobeguinii extract part. A strong free-radical scavenging signal was observed for the targeted zone at $h R_{\mathrm{F}} 31$. In the $\alpha$-glucosidase assay (5), two inhibition bands were detected, whereby one was fitting to the unknown zone at $h R_{\mathrm{F}}$ 31. Further antidiabetic substances remained at the start zone. Any activities are not overlooked, as the whole sample is subjected to the assay, which reveals to be a strong advantage of the HPTLC technique. Compared to column-derived techniques, some compounds possibly do not pass the detector, as these remained at the adsorbent at the column head and were not discovered as bioactive compounds. The AChE (6) and BChE (7) assays indicated inhibiting compounds that may be useful against Alzheimer's disease. 

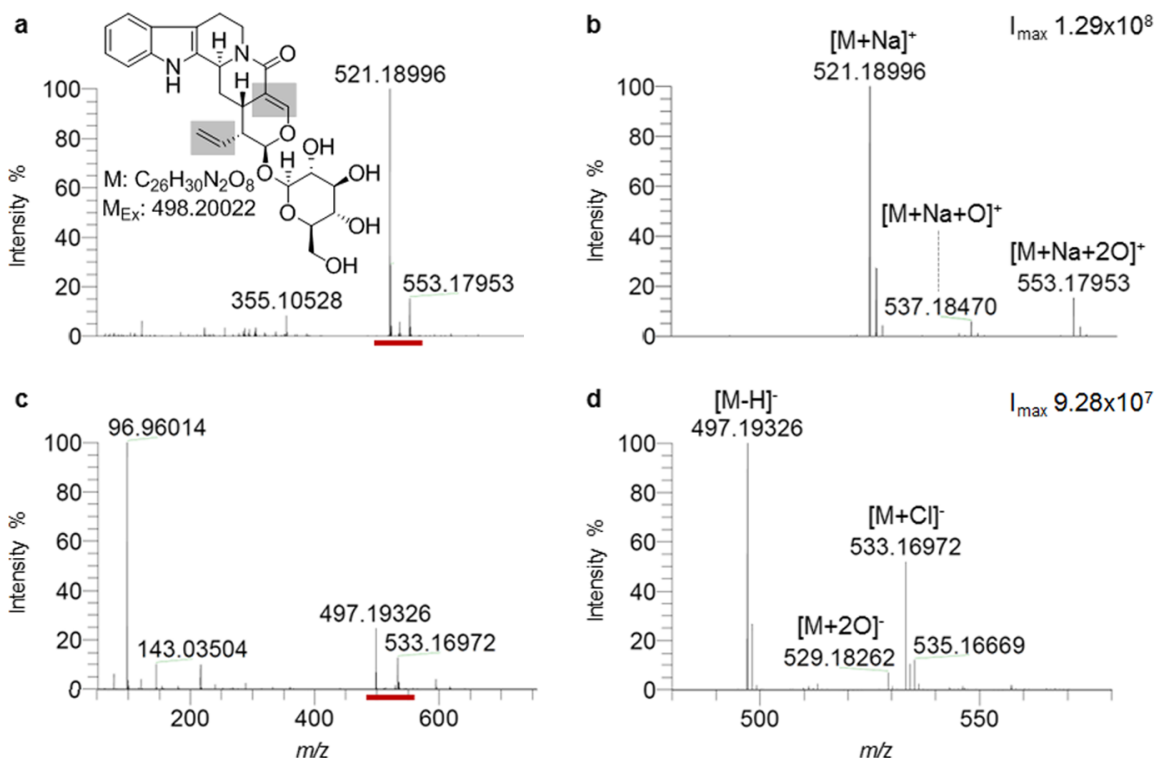

Figure 3. HPTLC-HRMS spectra recorded in the positive (a) and negative ionization (c) mode of the unknown zone at $h R_{\mathrm{F}} 31$ (substance proposed by accurate mass measurement) and zoom in the range of $m / z 480-580(\mathrm{~b}, \mathrm{~d})$.

Table 2. Observed $\left(m / z_{\text {obs }}\right)$ and Theoretical $\left(m / z_{\text {theo }}\right)$ Masses of the Recorded HPTLC-HRMS Mass Signals of the Zone at $h R_{\mathrm{F}} 31$ and the Predicted Molecular Formulas Based on Analysis of the Isotopic Pattern

$\begin{array}{ccccc}\text { signal } & m / z_{\text {obs }} & m / z_{\text {theo }} & \text { 土error }{ }^{a}[\mathrm{ppm}] & \text { molecular formula } \\ {[\mathrm{M}+\mathrm{Na}]^{+}} & 521.18996 & 521.18944 & 1.0 & {\left[\mathrm{NaC}_{26} \mathrm{H}_{30} \mathrm{~N}_{2} \mathrm{O}_{8}\right]^{+}} \\ {[\mathrm{M}+\mathrm{Na}+\mathrm{O}]^{+}} & 537.18470 & 537.18435 & 0.7 & {\left[\mathrm{NaC}_{26} \mathrm{H}_{30} \mathrm{~N}_{2} \mathrm{O}_{9}\right]^{+}} \\ {[\mathrm{M}+\mathrm{Na}+2 \mathrm{O}]^{+}} & 553.17953 & 553.17927 & 0.5 & {\left[\mathrm{NaC}_{26} \mathrm{H}_{30} \mathrm{~N}_{2} \mathrm{O}_{10}\right]^{+}} \\ {[\mathrm{M}-\mathrm{H}]^{-}} & 497.19326 & 497.19294 & 0.6 & {\left[\mathrm{C}_{26} \mathrm{H}_{29} \mathrm{~N}_{2} \mathrm{O}_{8}\right]^{-}} \\ {[\mathrm{M}-\mathrm{H}+2 \mathrm{O}]^{-}} & 529.18262 & 529.18277 & 0.3 & {\left[\mathrm{C}_{26} \mathrm{H}_{29} \mathrm{~N}_{2} \mathrm{O}_{10}\right]^{-}} \\ {[\mathrm{M}+\mathrm{Cl}]^{-}} & 533.16972 & 533.16962 & 0.2 & {\left[\mathrm{C}_{26} \mathrm{H}_{30} \mathrm{ClN}_{2} \mathrm{O}_{8}\right]^{-}} \\ { }^{a} \text { Mass accuracy error calculated according to the literature. }\end{array}$

The activity pattern looked similarly for both esterase assays. It was concluded that the targeted compound at $h R_{\mathrm{F}} 31$ was not selective for one of the two esterase assays. To conclude, the zone at $h R_{\mathrm{F}} 31$ showed activity in $\mathrm{DPPH}^{\bullet}, \alpha$-glucosidase, $\mathrm{AChE}$ and $\mathrm{BChE}$ assays, and thus, was of interest for further characterization.

HPTLC-HRMS of Multipotent Compound Zone. One out of the six plate pieces was still available for HRMS analysis of the targeted multipotent compound zone at $h R_{\mathrm{F}} 31$. HPTLC-HRMS is an advantageous technique to characterize substances in drug discovery, as only the active zone of interest is online eluted from the HPTLC layer and directly transferred into the HRMS system via an elution head-based interface. In the positive ionization mode, a base peak at $\mathrm{m} / z 521.18996$ was observed and assumed to be the sodium adduct $[M+$ $\mathrm{Na}]^{+}$(Figure 3a). According to the analysis of the isotopic pattern, the unknown compound was calculated to consist of 26 carbons, 2 nitrogens, and 8 oxygens. The molecular formula was assigned to be $\mathrm{C}_{26} \mathrm{H}_{30} \mathrm{~N}_{2} \mathrm{O}_{8}$ and the exact mass to be 498.20022 Da. Two oxidation products were found at $\mathrm{m} / \mathrm{z}$ $537.18470[\mathrm{M}+\mathrm{Na}+\mathrm{O}]^{+}$and $m / z 553.17953[\mathrm{M}+\mathrm{Na}+$ $2 \mathrm{O}]^{+}$(Figure $3 \mathrm{~b}$ ). All mass-dependent errors were $\leq 1 \mathrm{ppm}$ (Table 2).

The negative ionization was measured by alternating ionization in the same run; thus, only one zone was needed to be transferred into the HRMS. The deprotonated molecule was observed at $m / z 497.19326$ (Figure 3c) as well as the oxidation product at $\mathrm{m} / z 529.18262[\mathrm{M}+2 \mathrm{O}]^{-}$and chlorine adduct at $m / z 533.16972[\mathrm{M}+\mathrm{Cl}]^{-}$, most likely caused by the contaminated laboratory atmosphere (Figure 3c). Comparing our MS data with literature, ${ }^{10}$ the unknown compound zone at $h R_{\mathrm{F}} 31$ was assumed to be strictosamide. This substance was already found as main compound in the $80 \%$ ethanol extract of S. pobeguinii. ${ }^{15}$ Assumedly, all nonaromatic $\pi$-electrons were oxidized at the gray-highlighted structural positions (Figure 3a).

The assigned substance was confirmed by the strictosamide standard substance that was newly purchased. It gave similar mass signals (Figure S1). In addition, the fragmentation characteristics of the compound zone at $h R_{\mathrm{F}} 31$ was investigated.

Structural Information by Fragmentation. The fragmentation of the precursor ion isolated at $\mathrm{m} / z 521.2 \pm 0.4$ was investigated by recording the $\mathrm{MS}^{2}$ spectrum using a stepwise fragmentation, starting from normalized collision energy (NCE) 35 over 50-65. As observed by the $\mathrm{MS}^{2}$ experiment (Figure 4a), first the neutral loss could be assigned to be the saccharide moiety resulting in product ion $\mathbf{1}$ (Figure $4 \mathrm{~b}$ ).

Fragment 2 could appear mechanistically by a retro-DielsAlder reaction of the product ion $\mathbf{1}$ (Scheme S1) because it contained a double bond in a six-membered ring (Figure $4 b$, framed blue). Fragment 3 was observed after a hydride transfer of fragment 2 that resulted in a neutral loss of sodium hydride (Figure $4 \mathrm{~b}$ and Scheme S2). ${ }^{34}$ This fragment ion was assigned to be the only one found as non-sodium adduct. ${ }^{35}$ 

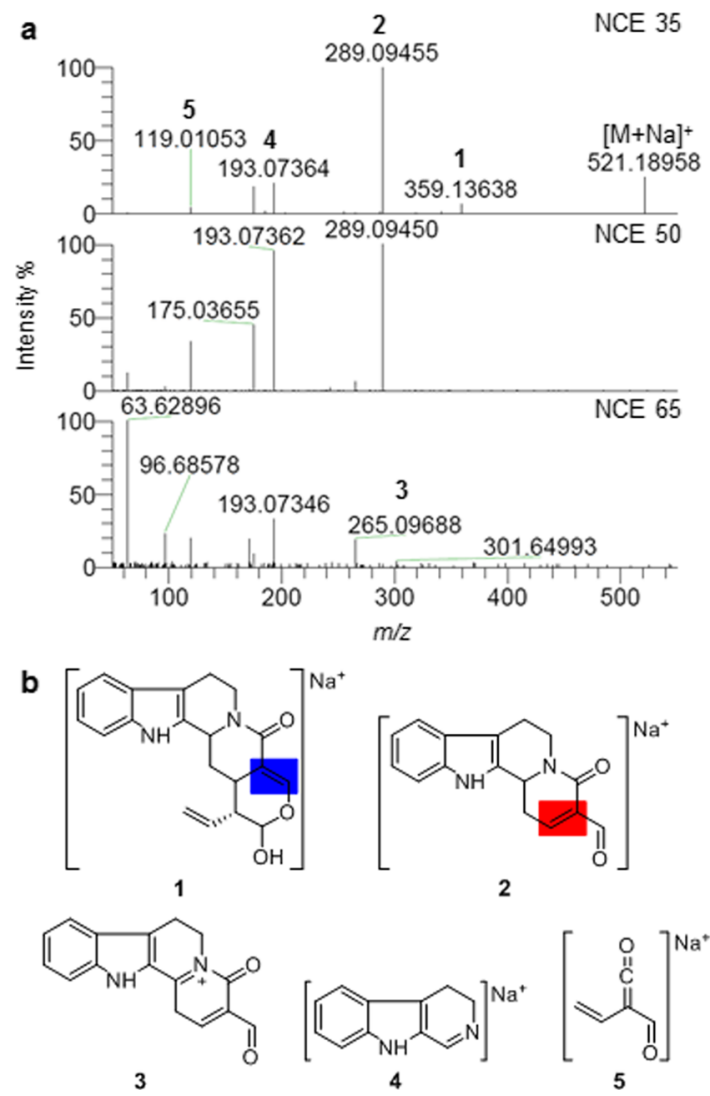

Figure 4. HPTLC-MS/MS spectra (a) with a mass isolation at $\mathrm{m} / \mathrm{z}$ $521.2 \pm 0.4$ recorded at a NCE of 35,50 , and 65 as well as proposed fragments 1-5 (b).

Fragment $\mathbf{2}$ similarly followed, as fragment $\mathbf{1}$, this pericyclic single-step process (Scheme S2) because of its nonaromatic $\pi$ bond in a six-membered heterocycle (Figure $4 b$, framed red). To the best of our knowledge, only the proposed molecule 2 was able to decompose into product ion 4. From the same, fragmentation reaction was also found the dien product 5 .

For this fragmentation study, all molecular formulas and mass-dependent errors of the fragments were summarized (Table 3). Also, fragment masses $m / z$ 175.03655, 96.68578,

Table 3. Observed $\left(m / z_{\text {obs }}\right)$ and Theoretical $\left(m / z_{\text {theo }}\right)$ Fragments by HPTLC-MS/MS of the Selected Mass Signal at $m / z 521.2 \pm 0.4$ of the Zone at $h R_{\mathrm{F}} 31$

\begin{tabular}{|c|c|c|c|c|}
\hline fragment & $m / z_{\text {obs }}$ & $m / z_{\text {theo }}$ & $\frac{ \pm \text { error }^{a}}{[\mathrm{ppm}]}$ & molecular formula \\
\hline 1 & 359.13638 & 359.13661 & 0.6 & {$\left[\mathrm{NaC}_{20} \mathrm{H}_{20} \mathrm{~N}_{2} \mathrm{O}_{3}\right]^{+}$} \\
\hline 2 & 289.09455 & 289.09475 & 0.7 & {$\left[\mathrm{NaC}_{16} \mathrm{H}_{14} \mathrm{~N}_{2} \mathrm{O}_{2}\right]^{+}$} \\
\hline 3 & 265.09688 & 265.09715 & 1.0 & {$\left[\mathrm{C}_{16} \mathrm{H}_{13} \mathrm{~N}_{2} \mathrm{O}_{2}\right]^{+}$} \\
\hline 4 & 193.07362 & 193.07362 & 0.0 & {$\left[\mathrm{NaC}_{11} \mathrm{H}_{10} \mathrm{~N}_{2}\right]^{+}$} \\
\hline 5 & 119.01053 & 119.01035 & 1.5 & {$\left[\mathrm{NaC}_{5} \mathrm{H}_{4} \mathrm{O}_{2}\right]^{+}$} \\
\hline
\end{tabular}

and 63.62896 were found, but not structurally assigned. Nevertheless, all found fragments were promising to support the hypothesis that our targeted compound zone at $h R_{\mathrm{F}} 31$ was strictosamide and was fitting to the reported fragmentation pattern of strictosamide. ${ }^{34}$ In addition, we found another fragmentation path, a hydride transfer to ion 3 and another fragment 5. This preliminary result was consistent to the fragmentation pattern observed by the reference compound (Figure S2).

Verification of the Unknown Zone to be Strictosamide. Apart from MS, both the unknown and the standard band at $h R_{\mathrm{F}} 31$ were not visible on the HPTLC plate under white light illumination (Figure S3, tracks 1 and 2), whereas at UV $366 \mathrm{~nm}$, both were observed as blue fluorescent bands of the same hue (Figure S3, tracks 3 and 4, marked). The HPTLC-UV/vis spectra of a standard zone and unknown zone at $h R_{\mathrm{F}} 31$ were recorded and overlaid. The almost identical spectra confirmed the unknown zone to be strictosamide (Figure S4). Hence, HPTLC-UV/vis/FLD chromatograms and HPTLC-UV/vis spectra verified the preliminary assignment to be correct.

\section{CONCLUSIONS}

The developed HPTLC-UV/vis/FLD-EDA-HRMS profiling of the unpolar S. pobeguinii bark extract was proven to be suited as an analytical concept for discovery of multipotent, active molecules. The molecular formula obtained by HPTLCHRMS from a multipotent, active zone fit to the molecule strictosamide. Additionally, two oxidation products of the nonaromatic $\pi$-electrons were found. As expected, the aromatic part stayed unoxidized. Its fragments fitted to the structure of strictosamide, which is an indole-derivative and $\mathrm{O}$-glycoside. By selective chemical derivatization with diphenylamine aniline phosphoric acid reagent and the neutral loss in the HPTLCMS/MS spectrum, it was proven that the targeted compound contained a saccharide moiety. The assignments were verified using the strictosamide standard for co-development as well as for comparison of UV/vis spectra, HRMS, and MS/MS spectra with the natural extract. The results of two biochemical assays were in accordance to the recently discovered $\mathrm{AChE} / \mathrm{BChE}$ inhibiting activities of strictosamide and proved the concept to be efficient. ${ }^{17}$ In two further performed assays, the observed antidiabetic and antioxidative activity of strictosamide in the $S$. pobeguinii extract is new. Hence, two new activities of strictosamide, that is, its antidiabetic and free-radical scavenging properties, were first discovered in this study using a straightforward hyphenated technique. Additionally, the unpolar bark extract showed activities at the start zone, which indicated further activities of more polar components of the bark to be studied in future. Diseases such as diabetes mellitus are increasing globally, and the potential of the presented streamlined hyphenation contributed to a fast discovery of new antidiabetic drugs found in natural sources.

\section{EXPERIMENTAL SECTION}

Chemicals and Materials. Toluene, acetone, chloroform, $n$-butanol, $i$-propanol, ethanol, acetic acid, ethyl acetate, $i$ propyl acetate, ethyl methyl ketone, formic acid, ammonia $25 \%, o$-phosphoric acid $85 \%$, and aniline were purchased from Carl Roth, Karlsruhe, Germany or Bernd Kraft, Duisburg, Germany. Strictosamide was obtained from AvaChem Scientific, San Antonio, USA. Fast blue salt B, diphenylamine, AChE from Electrophorus electricus Linnæus, BChE from horse serum, $\mathrm{DPPH}^{\bullet}$, and $\alpha$-glucosidase from baker's yeast were bought from Sigma-Aldrich, Steinheim, Germany. $\alpha$ Naphthyl acetate was from PANREAC (Barcelona, Spain). 2Naphthyl $\alpha$-D-glucopyranoside was purchased from Fluorochem, Hadfield, United Kingdom. Double distilled water was self-made with Heraeus Destamat Bi-18E, Thermo Fisher 
Scientific, Schwerte, Germany. Methanol for MS ( $\geq 99.9 \%$, optima LC/MS) was obtained from Thermo Fisher Scientific. HPTLC plates silica gel $60,20 \times 10 \mathrm{~cm}$, was from Merck, Darmstadt, Germany, prewashed by immersion with methanol-water, 2:1, v/v, and by development with dichloromethane; thereafter and in between, drying for $15 \mathrm{~min}$ at 120 ${ }^{\circ} \mathrm{C}$. In January 2010, S. pobeguinii bark pieces were collected in Lambarene, Gabon, followed by air-drying at $25{ }^{\circ} \mathrm{C}$. ${ }^{4}$ The identification was performed by $Y$. Issembe and R. Niangadouma, botanists at the National Herbarium of the Institute of Pharmacopea and Traditional Medicine. Voucher specimens were deposited there. ${ }^{4}$

Sample Preparation. An ethanolic solution of $1 \mathrm{mg} / \mathrm{mL}$ strictosamide was used as a reference standard. The $S$. pobeguinii ground bark extract was prepared by and obtained from the Laboratory of Natural Substances and Organometallic Synthesis, University of Sciences and Techniques of Masuku, Franceville, Gabon. Preparation procedure of the received extract: $100 \mathrm{~g}$ of plant material was extracted for $30 \mathrm{~min}$ in $1 \mathrm{~L}$ boiling water and filtrated and the filtrate was lyophilized to receive the extract. ${ }^{4}$ The prepared dry extract was dissolved in ethanol-water 2:1 (v/v) and stored in a fridge $(1 \mathrm{mg} / \mathrm{mL})$.

HPTLC-UV/Vis/FLD. Sample application was performed with the Automatic TLC Sampler 4 (ATS 4, CAMAG, Muttenz, Switzerland). As distance from the lower and left edges, $8 \mathrm{~mm}$ was chosen. The track distance was $\geq 10.5 \mathrm{~mm}$. The extract was applied in volumes of 10,20 , and $60 \mu \mathrm{L} /$ band for $5 \mathrm{~mm}$ bands, and for EDA, $100 \mu \mathrm{L}$ for $8 \mathrm{~mm}$ bands. The dosage speed was $120 \mathrm{~nL} / \mathrm{s}$; however, it was set to $300 \mathrm{~nL} / \mathrm{s}$ with nozzle heat at $60{ }^{\circ} \mathrm{C}$ for higher volumes applied $(\geq 60$ $\mu \mathrm{L})$. The starting zones were dried under an oil-pump vacuum for $5 \mathrm{~min}$. Developments with different MPs were performed in a twin through chamber $(20 \times 10 \mathrm{~cm}, \mathrm{CAMAG})$. Plate drying (until free of solvents) was adjusted to the different MPs. The plate image was captured by the TLC Visualizer, and all devices were controlled by winCATS software (both CAMAG). The absorption spectrum was measured between 200 and $700 \mathrm{~nm}$, using the TLC Scanner 4 (CAMAG) operated with deuterium and halogen/wolfram lamp at the data resolution of $1 \mathrm{~nm} /$ step and the scanning speed of 100 $\mathrm{nm} / \mathrm{s}$.

Postchromatographic Derivatization. HPTLC plates were derivatized by immersion (TLC Immersion Device III, CAMAG; vertical speed $4.5 \mathrm{~cm} / \mathrm{s}$, immersion time $0 \mathrm{~s}$ ) using the diphenylamine aniline phosphoric acid reagent. ${ }^{26,27}$ Therefore, $o$-phosphoric acid (85\%) was dropwise mixed with $2 \%$ acetone solutions each of diphenylamine and aniline $(1: 5: 5, \mathrm{v} / \mathrm{v} / \mathrm{v})$. The plate was heated at $117^{\circ} \mathrm{C}$ for $5 \mathrm{~min}$ and documented at UV $366 \mathrm{~nm}$ and white light illumination.

Effect-Directed Detection on the HPTLC Plate. As described, the chromatograms were immersed into a $0.02 \%$ methanolic DPPH ${ }^{\bullet}$ solution, ${ }^{28,29} \alpha$-glucosidase, ${ }^{30}$ and AChE/ BChE assays. ${ }^{31}$ Fast blue salt B together with 2-naphthyl $\alpha$-Dglucopyranoside or $\alpha$-naphthyl acetate was used as substrates for the $\alpha$-glucosidase or $\mathrm{AChE} / \mathrm{BChE}$ assays, respectively. For the $\mathrm{DPPH}^{\bullet}$ reagent, the plate was kept in the dark for $90 \mathrm{~s}$ and then heated at $60{ }^{\circ} \mathrm{C}$ for $90 \mathrm{~s}$. All images were documented at white light illumination.

High-Performance Thin-Layer ChromatographyHigh-Resolution Mass Spectrometry. The bioactive zone of interest was eluted via an oval elution head (cutting edge of $4 \times 2 \mathrm{~mm}$ ) with methanol at a flow rate of $0.1 \mathrm{~mL} / \mathrm{min}$ using the Plate Express (Advion, Ithaca, NY, USA) connected to the
Q Exactive Plus Hybrid Quadrupole-Orbitrap Mass Spectrometer (Thermo Fisher Scientific). An inline filter was mounted between the interface and the mass spectrometer containing a $0.5 \mathrm{~mm}$ stainless steel frit (Upchurch Scientific A356 and PEEK-Frit Blue UPA-703, Techlab, Erkerode, Germany) to prevent solid particles entering the mass spectrometer. $^{32}$ A heated electrospray ionization (HESI-II) was used as an ion source. Data were generated with Xcalibur 3.0.63 software (Thermo Fisher Scientific). High-resolution mass spectra were recorded in the range of $\mathrm{m} / z 50-750$ as full scan at a resolution of $280000 . \mathrm{MS}^{2}$ spectra were recorded by parallel reaction monitoring with mass isolation of the target molecule, isolation window of $\mathrm{m} / z 0.4$ at a resolution of 35000 and a fixed first mass of $m / z 50$.

\section{ASSOCIATED CONTENT}

\section{Supporting Information}

The Supporting Information is available free of charge on the ACS Publications website at DOI: 10.1021/acsomega.8b02462.

Proposed fragmentation mechanism of ion 1 to 2 ; proposed fragmentation mechanism of ion 2 to 3, 4, and 5 ; HPTLC-HRMS spectrum of standard zone; HPTLC-MS/MS spectra of standard zone; co-developed standard substance with the extract; and absorption spectra of unknown and standard zone (PDF)

\section{AUTHOR INFORMATION}

\section{Corresponding Authors}

*E-mail: Imanuel.Yuece@chemie.uni-giessen.de (I.Y.).

*E-mail: ahuguette2001@yahoo.fr (H.A.).

*E-mail: Gertrud.Morlock@uni-giessen.de (G.E.M.).

ORCID

Gertrud E. Morlock: 0000-0001-9406-0351

\section{Author Contributions}

H.A. delivered the ground bark dry extract. I.Y. performed all experiments supervised by G.E.M. I.Y. wrote the manuscript draft, and G.E.M. revised it.

\section{Notes}

The authors declare no competing financial interest.

\section{ACKNOWLEDGMENTS}

Thanks to Dr. Salim Hage and Maryam Jamshidi-Aidji for assay support, and to Merck, Darmstadt, Germany, for support with HPTLC plates. We are grateful to Elvis Jolinom Mbot, Ousmane Keita for the preparation of the plant dry extract.

\section{REFERENCES}

(1) Kuete, V.; Efferth, T. African Flora Has the Potential to Fight Multidrug Resistance of Cancer. BioMed Res. Int. 2015, 2015, 1-24.

(2) Jiofack, T.; Fokunang, C.; Guedje, N.; Kemeuze, V. Ethnobotany and Phytomedicine of the Upper Nyong Valley Forest in Cameroon. Afr. J. Pharm. Pharmacol. 2009, 3, 144-150.

(3) Igoli, J. O.; Ogaji, O. G.; Tor-Anyiin, T. A.; Igoli, N. P. Traditional Medicine Practice amongst the Igede People of Nigeria. Afr. J. Tradit., Complementary Altern. Med. 2005, 2, 134-152.

(4) Agnaniet, H.; Mbot, E. J.; Keita, O.; Fehrentz, J.-A.; Ankli, A.; Gallud, A.; Garcia, M.; Gary-Bobo, M.; Lebibi, J.; Cresteil, T.; et al. Antidiabetic Potential of Two Medicinal Plants Used in Gabonese Folk Medicine. BMC Complement Altern. Med. 2016, 16, 71. 
(5) Baldé, N. M.; Youla, A.; Baldé, M. D.; Kaké, A.; Diallo, M. M.; Baldé, M. A.; Maugendre, D. Herbal medicine and treatment of diabetes in Africa: an example from Guinea. Diabetes Metab. 2006, 32, 171-175.

(6) Raponda, W. A. Usages Pharmaceutiques Des Plantes Spontanées Du Gabon; Bulletin the Institute of Central Studies, 1952.

(7) Pope, G. V., Ed. Flora Zambesiaca, vol. 5, part 3; Royal Botanic Gardens, Kew: London, 2003; pp 379-720.

(8) Baldé, N. M.; Youla, A.; Baldé, M. D.; Kaké, A.; Diallo, M. M.; Baldé, M. A.; Maugendre, D. Herbal medicine and treatment of diabetes in Africa: an example from Guinea. Diabetes Metab. 2006, 32, 171-175.

(9) Martins, D.; Nunez, C. Secondary Metabolites from Rubiaceae Species. Molecules 2015, 20, 13422-13495.

(10) Mesia, K.; Cimanga, R. K.; Dhooghe, L.; Cos, P.; Apers, S.; Totté, J.; Tona, G. L.; Pieters, L.; Vlietinck, A. J.; Maes, L. Antimalarial Activity and Toxicity Evaluation of a Quantified Nauclea Pobeguinii Extract. J. Ethnopharmacol. 2010, 131, 10-16.

(11) Mesia, K.; Tona, L.; Mampunza, M.; Ntamabyaliro, N.; Muanda, T.; Muyembe, T.; Cimanga, K.; Totté, J.; Mets, T.; Pieters, L.; et al. Antimalarial Efficacy of a Quantified Extract ofNauclea pobeguiniiStem Bark in Human Adult Volunteers with Diagnosed Uncomplicated Falciparum Malaria. Part 1: A Clinical Phase IIA Trial. Planta Med. 2012, 78, 211-218.

(12) Njoya, E. M.; Munvera, A. M.; Mkounga, P.; Nkengfack, A. E.; McGaw, L. J. Phytochemical Analysis with Free Radical Scavenging, Nitric Oxide Inhibition and Antiproliferative Activity of Sarcocephalus Pobeguinii Extracts. BMC Complement Altern. Med. 2017, 17, 199.

(13) Jolinom, M. E.; Huguette, A.; Florence, N. T.; Stephane, P. G.; Theophile, D. Antidiabetic Activity of the Aqueous Extracts of Sarcocephalus Pobeguinii (Barks) and Nauclea Diderichii (Leaves and Barks) in Normal and Streptozotocin Induced Hyperglycemic Rats. Int. J. Adv. Res. 2017, 5, 974-982.

(14) Xu, Y.-J.; Foubert, K.; Dhooghe, L.; Lemière, F.; Cimanga, K.; Mesia, K.; Apers, S.; Pieters, L. Chromatographic Profiling and Identification of Two New Iridoid-Indole Alkaloids by UPLC-MS and HPLC-SPE-NMR Analysis of an Antimalarial Extract from Nauclea Pobeguinii. Phytochem. Lett. 2012, 5, 316-319.

(15) Dhooghe, L.; Mesia, K.; Kohtala, E.; Tona, L.; Pieters, L.; Vlietinck, A.; Apers, S. Development and Validation of an HPLCMethod for the Determination of Alkaloids in the Stem Bark Extract of Nauclea Pobeguinii. Talanta 2008, 76, 462-468.

(16) Li, Z.; Li, Z.; Lin, Y.; Meng, Z.; Ding, G.; Cao, L.; Li, N.; Liu, W.; Xiao, W.; Wu, X.; et al. Synthesis and Biological Evaluation of Strictosamide Derivatives with Improved Antiviral and Antiproliferative Activities. Chem. Biol. Drug Des. 2015, 86, 523-530.

(17) Kuete, V.; Sandjo, L. P.; Mbaveng, A. T.; Seukep, J. A.; Ngadjui, B. T.; Efferth, T. Cytotoxicity of Selected Cameroonian Medicinal Plants and Nauclea Pobeguinii towards Multi-Factorial Drug-Resistant Cancer Cells. BMC Complement Altern. Med. 2015, 15, 309.

(18) Liew, S. Y.; Khaw, K. Y.; Murugaiyah, V.; Looi, C. Y.; Wong, Y. L.; Mustafa, M. R.; Litaudon, M.; Awang, K. Natural Indole Butyrylcholinesterase Inhibitors from Nauclea Officinalis. Phytomedicine 2015, 22, 45-48.

(19) Li, D.; Chen, J.; Ye, J.; Zhai, X.; Song, J.; Jiang, C.; Wang, J.; Zhang, H.; Jia, X.; Zhu, F. Anti-inflammatory effect of the six compounds isolated from Nauclea officinalis Pierrc ex Pitard, and molecular mechanism of strictosamide via suppressing the NF- $\kappa \mathrm{B}$ and MAPK signaling pathway in LPS-induced RAW 264.7 macrophages. J. Ethnopharmacol. 2017, 196, 66-74.

(20) Jamshidi-Aidji, M.; Morlock, G. E. From Bioprofiling and Characterization to Bioquantification of Natural Antibiotics by Direct Bioautography Linked to High-Resolution Mass Spectrometry: Exemplarily Shown for Salvia Miltiorrhiza Root. Anal. Chem. 2016, 88, 10979-10986.

(21) Móricz, Á. M.; Ott, P. G.; Häbe, T. T.; Darcsi, A.; Böszörményi, A.; Alberti, Á.; Krüzselyi, D.; Csontos, P.; Béni, S.; Morlock, G. E. Effect-Directed Discovery of Bioactive Compounds Followed by Highly Targeted Characterization, Isolation and Identification,
Exemplarily Shown for Solidago Virgaurea. Anal. Chem. 2016, 88, $8202-8209$

(22) Klingelhöfer, I.; Morlock, G. E. Bioprofiling of Surface/ Wastewater and Bioquantitation of Discovered Endocrine-Active Compounds by Streamlined Direct Bioautography. Anal. Chem. 2015, 87, 11098-11104.

(23) Klingelhöfer, I.; Morlock, G. E. Sharp-Bounded Zones Link to the Effect in Planar Chromatography-Bioassay-Mass Spectrometry. J. Chromatogr. A 2014, 1360, 288-295.

(24) Morlock, G. E.; Klingelhöfer, I. Liquid ChromatographyBioassay-Mass Spectrometry for Profiling of Physiologically Active Food. Food Anal. Chem. 2014, 86, 8289-8295.

(25) Grzelak, E. M.; Hwang, C.; Cai, G.; Nam, J.-W.; Choules, M. P.; Gao, W.; Lankin, D. C.; McAlpine, J. B.; Mulugeta, S. G.; Napolitano, J. G.; et al. Bioautography with TLC-MS/NMR for Rapid Discovery of Anti-Tuberculosis Lead Compounds from Natural Sources. ACS Infect. Dis. 2016, 2, 294-301.

(26) Damonte, A.; Lombard, A.; Tourn, M. L.; Cassone, M. C. A Modified Solvent System and Multiple Detection Technique for the Separation and Identification of Mono- and Oligosaccharides on Cellulose Thin Layers. J. Chromatogr. A 1971, 60, 213-217.

(27) Bailey, R. W.; Bourne, E. J. Colour Reactions given by Sugars and Diphenylamine-Aniline Spray Reagents on Paper Chromatograms. J. Chromatogr. A 1960, 4, 206-213.

(28) Krüger, S.; Bergin, A.; Morlock, G. E. Effect-directed analysis of ginger ( Zingiber officinale ) and its food products, and quantification of bioactive compounds via high-performance thin-layer chromatography and mass spectrometry. Food Chem. 2018, 243, 258-268.

(29) Morlock, G. E.; Lapin, T. Effect-directed analysis of Pimpinella saxifraga L. root extract via HPTLC-UV/Vis/FLD-EDA-MS. J. Planar Chromatogr.-Mod. TLC 2018, 31, 79-86.

(30) Simões-Pires, C. A.; Hmicha, B.; Marston, A.; Hostettmann, K. A TLC Bioautographic Method for the Detection of $\alpha$ - and $\beta$ Glucosidase Inhibitors in Plant Extracts. Phytochem. Anal. 2009, 20, $511-515$

(31) Hage, S.; Morlock, G. E. Bioprofiling of Salicaceae Bud Extracts through High-Performance Thin-Layer Chromatography Hyphenated to Biochemical, Microbiological and Chemical Detections. J. Chromatogr. A 2017, 1490, 201-211.

(32) Morlock, G. E. Background Mass Signals in TLC/HPTLC-ESIMS and Practical Advices for Use of the TLC-MS Interface. J. Liq. Chromatogr. Relat. Technol. 2014, 37, 2892-2914.

(33) Knolhoff, A. M.; Callahan, J. H.; Croley, T. R. Mass Accuracy and Isotopic Abundance Measurements for HR-MS Instrumentation: Capabilities for Non-Targeted Analyses. J. Am. Soc. Mass Spectrom. 2014, 25, 1285-1294.

(34) Chai, Y.; Jiang, K.; Pan, Y. Hydride transfer reactions via ionneutral complex: fragmentation of protonated $\mathrm{N}$-benzylpiperidines and protonated $\mathrm{N}$-benzylpiperazines in mass spectrometry. J. Mass Spectrom. 2010, 45, 496-503.

(35) Li, Q.; Zhang, Y.; Wu, B.; Qu, H. Identification of Indole Alkaloids in Nauclea Officinalis Using High-Performance Liquid Chromatography Coupled with Ion Trap and Time-of-Flight Mass Spectrometry. Eur. J. Mass Spectrom. 2011, 17, 277. 